\title{
The Congruence of Enterprise Owner and Manager in Internal Locus of Control and Turnover Intention: The Mediating Role of Role Conflict
}

\author{
Bo $\mathrm{He}^{*}$, Yue Yuan \\ South West University of Science and Technology, China \\ ${ }^{*}$ Corresponding author: Bo He, associate professor, South West University of Science and \\ Technology, Email:heboswust@126.com
}

\begin{abstract}
Based on prior research on internal locus of control and person-environment fit, we examined the effect of the congruence of enterprise owner and manager internal locus of control on role conflict, which in turn influences manager's turnover intention. Results of cross-level polynomial regressions on 173 dyads supported the congruence effect hypothesis. Furthermore, asymmetrical incongruence effects were found when managers had lower role conflict and poorer turnover intention and their internal locus of control was lower than their leaders' as compared with when their internal locus of control was higher. These findings highlight the pivotal roles played by enterprise owner in reducing role conflict and turnover intention of manager.
\end{abstract}

Key words: enterprise owner's internal locus of control; manager's internal locus of control; role conflict; turnover intention

\section{Introduction}

In recent years organizations have been struggling to find effective ways to lower employee turnover $^{12}$. With the growing emphasis on individuals' personal control over their careers and external mobility ${ }^{3}$, workers today are likely to have weaker intentions to stay, even at organizational entry, than was the case when careers were characterized by stability ${ }^{4}$. Rousseau ${ }^{5}$ suggested two core ways that organizations can retain employees: enhancing employees' perceptions of organizational membership and actively demonstrating to them that they are cared for and valued, even though their employment may be temporary. Of the two, more organizations will choose the latter. From the long-term practice of enterprises, however, it would not fundamentally solve the problem of employee turnover. Referring to Rousseau's first viewpoint, this study uses internal and external locus of control as an entry point to study the problem of organizers' turnover from the perspectives of both individuals and organizations. In theory, it not only verifies Rousseau's points of view, but also enriches the literature research related to locus of control. In practice, it can provide useful reference and suggestion for organizations to reduce internal contradictions and retain core talents.

\section{Theory and hypothesis}

Enterprise owner - manager congruence in personal characteristics has been an important line of research in both the relational demography literature ${ }^{6}$ and the person-environment fit literature (particularly in regard to person-supervisor fit $^{7}$ ). Rotter $^{8}$ differentiated between internal and external locus of control. Internals are those who believe they are the masters of their fate and therefore often are confident, alert, and directive in attempting to control their 
external environments ${ }^{9}$. Furthermore, they often perceive a strong link between their actions and consequences. Strong perceptions of organizational membership exist when individuals and the organization have common interests and individuals perceive that their relationship to the organization forms a sense of "us". External efforts are of great importance for enterprise owner and manager to form the sense of "us". Nevertheless, if the internal locus of control of manager is congruent with enterprise owner, it will be more beneficial to forming the sense of "us" and reducing the role conflict between the two. Day et al. ${ }^{10}$ study found that flexibility of personality traits can predict role stress. Previous research has shown that internals would perceive lower levels of role overload, role ambiguity, role conflict and job stress than externals 错误!末定义书签。

Hypothesis1. The more aligned a manager's and his or her enterprise owner's levels of internal locus of control are (i.e., higher congruence), the lower the role conflict is.

Enterprise owners and managers can be congruent at either high or low levels of internal locus of control. Internal control employees always seek out ways to improve their work life, when an internal control manager teams up with an internal control enterprise owner, their common understanding of work goals may encourage them to exert effort to achieve a lower role conflict. In contrast, when enterprise owner and manager are congruent at low levels of internal locus of control, although they have a common goal—which may still result in a higher role conflict - this goal entails passively adapting to the environment. When both parties aim to maintain the status quo, the manager is likely to receive positive reinforcement for withholding his or her efforts for improvement. Because of a lack of effort, managers and enterprise owners with low levels of internal locus of control are less likely to develop relationships that have quality as high as do those between highly internal control managers and enterprise owners.

Hypothesis2. Role conflict is lower when a manager is aligned with an enterprise owner at a high level of internal locus of control rather than when a manager is aligned with an enterprise owner at a low level of internal locus of control.

It is also important to differentiate two scenarios of leader-follower incongruence in internal locus of control. We expect the incongruence effect to be asymmetrical in such a way that it is more detrimental to role conflict when the manager has a higher level of internal locus of control than the enterprise owner. Despite of the higher internal locus of control of the manager, the leader-member relationship is mostly decided by the leader whose influence is stronger under Chinese culture. If the enterprise owner is a low internals and always attributes the reason to the outside world or the subordinate, the subordinate will believe that the leader is too radical or incompetent, and thus causes the highest role conflict. On the other hand, when there is incongruence and the enterprise owner has higher internal locus of control than the manager, although compared with the former inconsistency, the role conflict is lower because the enterprise owner attributes the responsibility to himself instead of putting the blame on the subordinate.

Hypothesis3. Role conflict is higher when a manager's internal locus of control is higher than an enterprise owner's rather than when an enterprise owner's internal locus of control is higher than a manager's.

Schneider ${ }^{11}$ proposed the Attraction-Selection-Attrition theory which assumed that people prefer to work with those whose personality traits are similar to theirs and those who think 
themselves are not matching the group choose to leave. Pendergrass ${ }^{12}$ examined that whether the personality type of employee and their similarities can predict employee turnover. The study found that the matching degree of various personalities between the subordinate and the manager directly impact on the latter's work attitude, including organizational commitment, turnover intention, satisfaction to the manager, etc. A large number of studies have shown that Person-Environment fit is a function of the interaction between person and environment, and good fit has positive impact on person. On the contrary, the mismatching of person and

environment can result in serious consequences, such as withdrawal behaviour ${ }^{13}$, turnover intention ${ }^{14}$, etc. Daystudy found that flexibility which belongs to personality traits can predict job-related attitude variables, e.g. role stress, job satisfaction, turnover intention and so on. In addition, role stress together with job satisfaction is the mediator variable between personality traits and turnover intention.

Hypothesis4. Role conflict mediates the relationship between manager-enterprise owner congruence/incongruence in internal locus of control and manager turnover intention.

\section{Methods}

Data was collected from Chinese private enterprises. The final sample consists of 29 enterprise owners and an average of 6 managers in each enterprise.

Internal locus of control. A six-item scale developed by Rotterwas used to measure enterprise owner's and manager's internal locus of control. Participants responded to these items on a scale from 1to 5. A sample item was: "Job opportunities are created by me" and "I decided the doings of myself”. The scale’s reliability was 0.744 and 0.846 .

Role conflict. A six-item scale developed by Rizzo et al ${ }^{15}$ was used to measure manager's role conflict. Participants responded to these items on a scale from 1 to 5 . A sample item was: "I know what the boss wants from me". The scale's reliability was 0.869 .

Turnover intention. A four-item scale developed by Kelloway ${ }^{16}$ was used to measure manager's turnover intention. A sample item was: "I am thinking about leaving this organization". The scale's reliability was 0.742 .

Control variable. Studies show that demographic and professional factors will affect subject's turnover intention. Therefore, this study made age, gender, marital status, and education as control variables.

\section{Results}

As shown in the table 1, Enterprise owner's internal locus of control was negatively correlated with role conflict $(\mathrm{r}=-0.61, \mathrm{p}<.01)$ and turnover intention $(\mathrm{r}=-0.50, \mathrm{p}<.01)$. Manager' $s$ internal locus of control was negatively correlated with role conflict $(r=-0.41, p$ $<.01)$ and turnover intention $(\mathrm{r}=-0.33, \mathrm{p}<.01)$.

Table 2 shows the results of model fit comparisons. The hypothesized four-factor model shows satisfactory fit $\left(X^{2}=192.011, \mathrm{Df}=187, \mathrm{p}>.05, \mathrm{NFI}=0.896, \mathrm{IFI}=0.997, \mathrm{CFI}=.997\right.$, TLI=.996, RMR=.039, and RMSEA =.012) and has significantly better fit than all of the alternative models. 
Table1. Means, standard deviations, and correlations

\begin{tabular}{lcccccccccc}
\hline \multicolumn{1}{c}{ Variables } & Mean & SD & 1 & 2 & 3 & 4 & 5 & 6 & 7 \\
\hline 1. Age & 2.17 & .70 & 1 & & & & & & \\
2. Gender & 1.43 & .49 & $-.25^{* *}$ & 1 & & & & & \\
3. Marital status & 1.34 & .52 & $-.37^{* *}$ & $.22^{* *}$ & 1 & & & & \\
4. Educations & 2.54 & .78 & .06 & -.13 & .05 & 1 & & & \\
5.Enterprise owner internal locus of control(time1) & 3.93 & .65 & $.19^{*}$ & .04 & -.07 & .06 & 1 & & \\
6. Manager internal locus of control(time1) & 3.59 & .59 & .01 & .12 & .03 & -.02 & $.68^{* *}$ & 1 & \\
7. Role Conflict(time2) & 2.22 & .76 & -.12 & -.10 & $.17^{*}$ & .02 & $-.61^{* *}$ & $-.41^{* *}$ & 1 \\
8. Turnover intention(time2) & 2.44 & .73 & $-.19^{* *}$ & .05 & $.33^{* *}$ & .11 & $-.50^{* *}$ & $-.33^{* *}$ & $.47^{* *}$ & 1 \\
\hline
\end{tabular}

Note. $\mathrm{N}=173$. ** $\mathrm{P}<0.01 * \mathrm{P}<0.05$.

Table2. Model fit Results for confirmatory factor analyses

\begin{tabular}{lcccccccc}
\hline \multicolumn{1}{c}{ Models } & $\mathrm{X}^{2}$ & $\mathrm{Df}$ & RMSEA & RMR & NFI & IFI & TLI & CFI \\
\hline 1. Hypothesized four-factor model & 192.011 & 187 & .012 & .039 & .896 & .997 & .996 & .997 \\
2. Three-factor model & 282.159 & 197 & .05 & .053 & .846 & .948 & .938 & .947 \\
3. Two-factor model & 480.118 & 200 & .09 & .071 & .739 & .829 & .799 & .826 \\
4. Single-factor model & 508.765 & 203 & .094 & .072 & .723 & .813 & .783 & .810 \\
\hline
\end{tabular}

Note. $\mathrm{n}=173$. All alternative models were compared with the hypothesized four-factor model.

As shown in Table 3, the three second-order polynomial terms ${ }^{17}$ were jointly significant $(\mathrm{F}=14.456, \mathrm{p}<.001)$, and the surface along the incongruence line curved downward (curvature=1.86, $\mathrm{p}<.01$ ), thus supporting Hypothesis 1 .

Table3. Cross-Level polynomial regressions of role conflict and turnover intention on internal locus of control congruence/incongruence

\begin{tabular}{lccc}
\hline & & \multicolumn{2}{c}{ Turnover intention } \\
\cline { 3 - 4 } \multicolumn{1}{c}{ Variables } & Role conflict & M1 & M2 \\
\hline Constant & $1.989^{* *}$ & $1.609^{* *}$ & $1.389^{* *}$ \\
Age & 0.039 & 0.031 & 0.027 \\
Gender & -0.169 & 0.012 & 0.031 \\
Marital status & 0.15 & 0.296 & 0.279 \\
Education & 0.028 & 0.105 & 0.102 \\
Enterprise owner internal locus of control(E) & $-0.555^{* *}$ & $-0.358^{* *}$ & $-0.298^{*}$ \\
Manager internal locus of control(M) & -0.113 & -0.189 & -0.176 \\
$\mathrm{E}^{2}$ & $0.432^{*}$ & $0.519^{* *}$ & 0.472 \\
$\mathrm{E}^{*} \mathrm{M}$ & $-0.951^{* *}$ & $-1.289^{* *}$ & $-1.185^{* *}$ \\
$\mathrm{M}^{2}$ & $0.477^{*}$ & $0.574^{* *}$ & $0.522^{* *}$ \\
Role conflict & & & 0.109 \\
$\mathrm{R}^{2}$ & 0.444 & 0.451 & 0.458 \\
Congruence (E=M) line Slope & $-0.668^{* *}$ & $-0.547^{*}$ & $-0.474^{*}$ \\
Curvature & -0.042 & -0.196 & -0.191 \\
Incongruence (E= -M) line Slope & $-0.442^{*}$ & -0.169 & -0.122 \\
Curvature & $1.86^{* *}$ & $2.382^{* *}$ & $2.179^{* *}$ \\
F for the 3 quadratic terms & $14.456^{* *}$ & $14.895^{* *}$ & $13.707^{* *}$ \\
\hline
\end{tabular}

Note. $\mathrm{n}=173 ;{ }^{* *} \mathrm{p}<0.01, * \mathrm{p}<0.05$. Standardized regression coefficients are reported. 


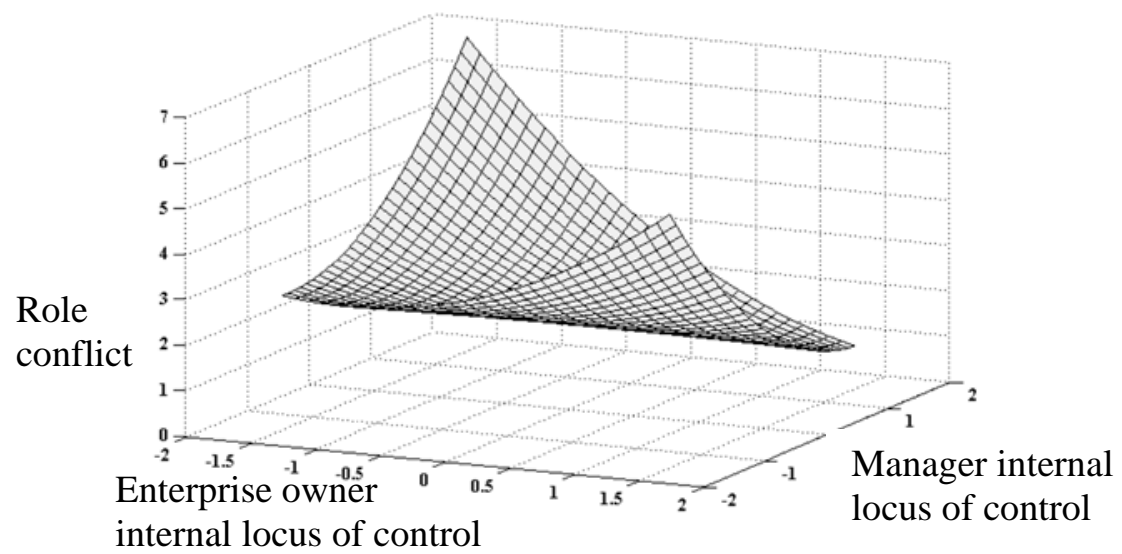

Figure1. Congruence effect and asymmetrical incongruence effect of Enterprise owner and Manager internal locus of control on role conflict

The slope along the congruence line is negative $(-0.042)$, indicating that the high-high congruence condition has lower role conflict than the low-low congruence condition. The response surface in Figure 1 also indicates that role conflict is lower at the right corner (high/high congruence) than at the left corner (low/low congruence), thus supporting Hypothesis 2. The quantity representing the lateral shift is significant and negative $(-0.442$, $\mathrm{p}<0.05$ ), indicating a shift toward the region where $\mathrm{E}$ is lesser than $\mathrm{M}$, thus, supporting Hypothesis 3. As shown in Table 4, the indirect effect of congruence/incongruence, via role conflict, is significant for turnover intention (.07, $\mathrm{p}<.05)$, thus, supporting Hypothesis 4.

Table4. Results from tests of direct and indirect effects of congruence internal locus of control on turnover intention

\begin{tabular}{lcc}
\hline \multicolumn{1}{c}{ Variables } & Role conflict & Turnover intention \\
\hline Coefficient of the block variable (i.e., direct effect of congruence) & $0.642^{* *}$ & $0.527^{* *}$ \\
Coefficient of role conflict $(\gamma$ role conflict $)$ & - & 0.109 \\
Indirect effect of congruence via role conflict $\quad\left(=0.642^{*} \gamma_{\text {role }}\right.$ & - & $0.07^{* *}$ \\
conflict $)$ & & $(-0.2998,0.4969)$ \\
$95 \%$ bootstrapped confidence intervals for the indirect effect & &
\end{tabular}

Note. $\mathrm{n}=173 ;{ }^{* *} \mathrm{p}<0.01,{ }^{*} \mathrm{p}<0.05$. Standardized coefficients are reported.

\section{Discussions}

The findings of this study have several important theoretical implications. Firstly, by integrating enterprise owner characteristics as well as the person-environment fit framework into the study of internal locus of control and the associated manager's turnover intention, we extended internal locus of control research by revealing that enterprise owner internal locus of control influences the likelihood for manager internal locus of control to reduce manager's turnover. Secondly, contributing to the role conflict literature, this study drew upon goal congruence research and demonstrates that dyadic congruence at high versus low levels of internal locus of control led to different role conflict qualities. Thirdly, in the current study we demonstrate the partial mediating role of role conflict in linking enterprise owner - manager congruence/incongruence in internal locus of control to important outcomes for managers. By doing so, we posit dyadic exchange as one of the explanatory mechanisms for reaping the beneficial effects of person-supervisor fit. 
The findings of this study also have several important practical implications. Firstly, it is crucial for the members of a dyad to be aware of both parties' internal locus of control levels for favourable outcomes to be harvested. This could help avoid the potential "initiative paradox" for enterprise owners who themselves are low in internal locus of control. Secondly, it is important for organizations to ensure dyad-level congruence in internal control to reduce role conflict and turnover intention. Admittedly, enterprise owners in organizations typically do not have the luxury of selecting manager who matches with their internal locus of control levels. Rather, they are often assigned to lead an intact work team or group. When internal control enterprise owners are leading less internal control managers, we suggest these enterprise owners can improve dyadic goal congruence by using goal-setting procedures and frequent feedback giving and by providing developmental support and coaching to gradually cultivate lower role conflict with the less internal control employees.

Several limitations are associated with the current study. Firstly, the data were collected from the employees working in China. Specific Chinese cultural characteristics (e.g., high "power distance") may limit the generalizability of the results. Secondly, the current study was not conducted with an experimental design, and conclusions about causality are constrained. Finally, our study focused on enterprise owner-manager internal locus of control rather than on behavioural manifestations of their internal control personalities.

\section{References}

1. G.Chen, R. E. Ployhart, H. C. Thomas, N. Anderson, and P. D Bliese, The power of momentum: A new model of dynamic relationships between job satisfaction change and turnover intentions. Academy of Management Journal, 54 (2011)159-181.

2. D. M. Rousseau, Psychological contracts in the workplace: Understanding the ties that motivate. The Academy of Management Executive, 18(2004) 120-127.

3. J. Shane, J. Heckhausen, J. Lessard, C. Chen, and E. Greenberger, Career-related goal pursuit among post-high school youth: Relations between personal control beliefs and control strivings. Motivation and Emotion, 36(2012) 159-169.

4. T. W. Ng, and M. M. Butts, Effectiveness of organizational efforts to lower turnover intentions: The moderating role of employee locus of control. Human Resource Management, 48(2009) 289.

5. D. M. Rousseau, Why workers still identify with organizations. Journal of Organizational Behavior, 19(1998) 217-233.

6. A. S. Tsui, and C. A. O'reilly, Beyond simple demographic effects: The importance of relational demography in superior-subordinate dyads. Academy of management journal, 32(1989) 402-423.

7. T. W. Ng , K. L. Sorensen, \& L. T.Eby, Locus of control at work: a meta-analysis. Journal of organizational Behavior, 27(2006) 1057-1087.

8. J. B. Rotter, Generalized expectancies for internal versus external control of reinforcement. Psychological monographs: General and applied, 80(1966) 1.

9. E. J. Phares, Locus of control in personality. General Learning Press. (1976). 
10. D. V. Day, A. G. Bedeian, and J. M. Conte, Personality as Predictor of Work-Related Outcomes: Test of a Mediated Latent Structural Model1. Journal of Applied Social Psychology, 28(1998) 2068-2088.

11. B. Schneider, The people make the place. Personnel psychology, 40(1987) 437-453.

12. L. A. Pendergrass, Personality similarity as a predictor of organizational turnover: A test of attraction-selection-attrition theory. 2002.

13. J. Tak, Relationships between various person-environment fit types and employee withdrawal behavior: A longitudinal study. Journal of Vocational Behavior, 78(2011) 315-320.

14. M. A. Memon, R.Salleh, M. N. R.Baharom, and H. Harun, Person-Organization Fit and Turnover Intention: The Mediating Role of Employee Engagement. In International Conference on Leadership and Management (ICLM2014), Kuala Lumpur. 2014.

15. J. R. Rizzo, R. J. House, and S. I Lirtzman, Role conflict and ambiguity in complex organizations. Administrative science quarterly, 1970 150-163.

16. E. K.Kelloway, B. H.Gottlieb, and L. Barham, The source, nature, and direction of work and family conflict: a longitudinal investigation. Journal of occupational health psychology, 4(1999) 337.

17. Z. Zhang, M. O. Wang, and J. Shi, Leader-follower congruence in proactive personality and work outcomes: The mediating role of leader-member exchange. Academy of Management Journal, 55(2012) 111-130. 